\title{
PENGEMBANGAN APLIKASI MUNSELL SOIL COLOR DETECTION CHART INDEX MENGGUNAKAN METODE SUPPORT VECTOR MACHINE
}

\author{
Mungki Astiningrum ${ }^{1}$ Putra Prima Arhandi², Elly Fatmawati ${ }^{3}$ \\ 1,2Program Studi Teknik Informatika, Jurusan Teknologi Informasi, ${ }^{3}$ Politeknik Negeri Malang \\ ${ }^{1}$ mungki.polinema@gmail.com ,2 putraprima@polinema.ac.id, ${ }^{3}$ ellyfatmawati95@gmail.com
}

\begin{abstract}
Abstrak
Salah satu sifat tanah yang paling sering digunakan oleh para peneliti untuk menggambarkan dan mengklasifikasikan tanah adalah warna. Warna merupakan sifat fisik yang dapat memberikan informasi tentang beberapa karakteristik paling penting dari suatu tanah seperti, komposisi mineral, usia, dan proses pembentukan. Dengan mengetahui warna dari suatu tanah, maka dapat ditentukan kegunaan tanah tersebut apakah cocok untuk lahan pertanian, perkebunan, perumahan, dan lain sebagainya, disesuaikan dengan kondisi tanahnya. Dalam mengidentifikasi warna tanah, para peneliti menggunakan standar warna pada buku Munsell Soil Color Chart. Banyaknya variasi warna pada buku ini menyebabkan peneliti membutuhkan kecermatan dan waktu lama dalam penentuan warna tanah. Keterbatasan indera penglihatan manusia juga mampu menjadi faktor terjadinya kesalahan sehingga informasi yang diperoleh menjadi kurang akurat. Oleh karena itu, dikembangkanlah aplikasi menggunakan pengolahan citra digital untuk mengidentifikasi warna tanah berdasarkan Munsell Soil Color Chart menggunakan metode Support Vector Machine (SVM) dan ekstraksi fitur warna Modus dan Mean. Proses diawali dengan melakukan cropping terhadap citra tanah inputan menjadi 170x200, kemudian mengurangi noise pada citra masukan menggunakan median filter dan mengekstraksi fitur dengan Modus dan Mean. Selanjutnya proses training dan testing data menggunakan metode SVM. Pengujian yang dilakukan menghasilkan tingkat keakuratan mencapai 93,33\% untuk masing - masing ekstraksi.
\end{abstract}

Kata kunci: citra digital, deteksi warna tanah, Munsell Soil Color Chart, tanah

\section{Pendahuluan}

\subsection{Latar Belakang}

Tanah adalah bangunan alam yang tersusun atas horison-horison yang terdiri atas bahan mineral dan organik, biasanya tak padu, mempunyai tebal yang berbeda-beda dan yang berbeda pula dengan bahan induk yang ada di bawahnya dalam hal morfologi, sifat dan susunan fisik, sifat dan susunan kimia, dan sifat-sifat biologi Sutanto (2005). Salah satu sifat yang paling sering digunakan oleh para peneliti untuk menggambarkan dan mengklasifikasikan tanah adalah warna. Warna merupakan sifat fisik yang dapat memberikan informasi tentang beberapa karakteristik paling penting dari suatu tanah seperti, komposisi mineral, usia, dan proses pembentukan Jordan (2014). Hasil klasifikasi tanah selanjutnya dijadikan dasar penilaian kesesuaian lahan untuk pertanian, perhutanan, dan sebagainya.

Dalam penelitian sumberdaya tanah saat ini, peneliti menggunakan Munsell Soil Color Chart (MSCC) sebagai acuan penentuan warna tanah. Cara menggunakan MSCC ini adalah dengan membandingkan kemiripan warna tanah asli dengan pedoman warna yang ada dalam buku tersebut. Banyaknya variasi warna dalam buku ini mencapai lebih dari 276 macam warna membuat peneliti membutuhkan waktu yang lama dalam penentuan warna tanah. Belum lagi karena keterbatasan indera penglihatan manusia dalam pengenalan warna memungkinkan terjadinya kesalahan sehingga informasi yang diperoleh kurang akurat. Berdasarkan hal - hal tersebut, maka pada penelitian ini dibuatlah pengembangan suatu aplikasi menggunakan pengolahan citra digial untuk mengidentifikasi warna tanah berdasarkan Munsell Soil Color Chart menggunakan metode Support Vector Machine sebagai metode untuk pengklasifikasian warna tanah dan ekstraksi fitur warna Modus dan Mean dengan harapan bahwa aplikasi pada penelitian ini akan memberikan alternatif kepada peneliti dan pengguna lainnya untuk mempermudah dan mempercepat penentuan warna tanah dengan hasil yang akurat.

\subsection{Rumusan Masalah}

a. Bagaimana mengembangkan suatu aplikasi yang berfungsi untuk mendeteksi warna tanah 
menggunakan standar warna pada Munsell Soil Color Chart agar mempermudah dan mempercepat dalam penentuan warna tanah?

b. Bagaimana tingkat akurasi metode Support Vector Machine (SVM) dalam melakukan klasifikasi warna tanah?

\subsection{Batasan Masalah}

1. Data chart warna yang digunakan adalah 5 index warna yang diambil secara acak pada buku Munsell Soil Color Chart.

2. Warna tanah yang diklasifikasikan adalah warna top soil.

3. Informasi yang ditampilkan berupa klasifikasi index warna tanah yang diuji sesuai dengan pedoman Munsell Soil Color Chart.

\section{Landasan Teori}

2.1 Tanah

Salah satu komponen dari lahan yang merupakan komponen utama adalah tanah Hardjowigeno (1992). Tanah adalah kumpulan dari benda alam di permukaan bumi yang tersusun dalam horison-horison, terdiri dari campuran bahan mineral, bahan organik, air dan udara, dan merupakan media untuk tumbuhnya tanaman Hardjowigeno (1987).

\subsection{Warna Tanah}

Warna tanah berfungsi sebagai penunjuk dari sifat tanah, karena warna tanah dipengaruhi oleh beberapa faktor yang terdapat dalam tanah tersebut. Saat ini, untuk menentukan warna tanah peneliti membandingkan warna pada buku Munsell Soil Color Chart. Diagram warna baku Munsell disusun dalam tiga variable Madjid (2007) yaitu:

a. Hue merupakan warna spektrum yang dominan sesuai dengan panjang gelombangnya.

b. Value menunjukkan gelap terangnya warna sesuai dengan banyaknya sinar yang dipantulkan.

c. Chroma menunjukkan kemurnian atau kekuatan dari warna spektrum.

\subsection{Citra Digital}

Citra atau gambar dapat didefinisikan sebagai sebuah fungsi dua dimensi $\mathrm{f}(\mathrm{x}, \mathrm{y})$, di mana $\mathrm{x}$ dan $\mathrm{y}$ adalah koordinat bidang datar, dan harga fungsi $\mathrm{f}$ di setiap pasangan koordinat $(\mathrm{x}, \mathrm{y})$ disebut intensitas atau level keabuan (grey level) dari gambar di titik itu Hermawati (2013).

\subsection{Citra Berwarna RGB}

Red (Merah), Green (Hijau) dan Blue (Biru) merupakan warna dasar yang dapat diterima oleh mata manusia. Setiap pixel pada citra warna mewakili warna yang merupakan kombinasi dari ketiga warna dasar RGB. ). RGB didasarkan pada teori bahwa mata manusia peka terhadap panjang gelombang 630nm (merah), $530 \mathrm{~nm}$ (hijau), dan 450 nm (biru) Rizal (2014).

\subsection{Modus RGB}

Modus adalah nilai warna yang pixel yang paling sering muncul dalam suatu gambar Robbani (2016).

\subsection{Mean RGB}

Mean atau rata-rata adalah penjumlahan semua nilai yang terdapat pada masing-masing komponen R, G, dan B. Kemudian hasil dari penjumlahan tersebut dibagi dengan jumlah pixel yang terdapat dalam citra.

$$
\mu=\frac{x_{1}+x_{2}+\cdots+x_{n 1}}{N}
$$

Keterangan:

$$
\begin{array}{ll}
\mu & \text { : Rata-rata } \\
x_{n} & \text { : Nilai pixel } \\
\mathrm{N} & \text { : Jumlah keseluruhan pixel }
\end{array}
$$

\subsection{Median Filter}

Median filter merupakan order-statistics filter yang paling banyak diketahui, yang mana sesuai namanya, mengganti nilai pixel dengan median dari level intensitas dalam neighbourhood dari pixel itu Woods, dkk (2008).

$$
\begin{gathered}
f(x, y)=\operatorname{median}(g(s, t)\} \\
(s, t) \in S_{x y}
\end{gathered}
$$

\subsection{Normalisasi}

Normalisasi diperlukan untuk memperkecil range nilai dari data agar tidak terlalu besar. Normalisasi mempunyai banyak jenis salah satunya Normalisasi Data Sigmoid. Normalisasi ini memperkecil range nilai menjadi 0,1 hingga 0,9 Kusuma (2016).

$$
z^{\prime}=\frac{0.8(x-a)}{b-a}+0,1
$$

Keterangan:

$$
\begin{array}{ll}
z & \text { : nilai baru setelah dinormalisasi } \\
\boldsymbol{x} & \text { : data } \\
\boldsymbol{b} & \text { : nilai maximum dari data } \\
\boldsymbol{a} & \text { : nilai minimum dari data }
\end{array}
$$

\subsection{Support Vector Machine}

Support Vector Machine (SVM) merupakan suatu metode pembelajaran untuk mesin yang baru berdasarkan teori pembelajaran statistik yang diajukan oleh Vapnik di tahun 90an. Inti dari proses pelatihan pada SVM ini adalah usaha untuk 
mencari lokasi hyperplane. Hyperplane pemisah terbaik antara kedua kelas tersebut dapat ditemukan dengan mengukur margin hyperplane dan mencari titik maksimalnya. Margin merupakan jarak antara hyperplane tersebut dengan data terdekat dari masing-masing kelas. Data yang paling dekat inilah yang disebut support vector Kusuma (2016). Jika titik terpisah secara linear fungsi untuk permukaan ini ditentukan oleh persamaan 4 .
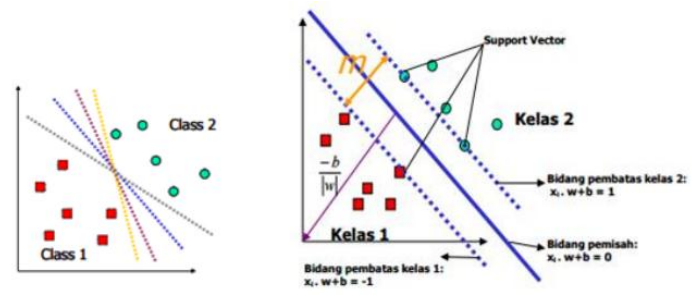

Gambar 1. Ilustrasi Pemisahan Kelas SVM

$$
\begin{aligned}
& f(x)=\operatorname{sign}\left(\sum_{i=1}^{2} a_{i} y_{i}\left(x_{i}, x\right)+b\right) \\
& \left(x_{i}, y_{1}\right) \in R^{N} x\{-1,1\}
\end{aligned}
$$

Dimana:

$$
\begin{array}{ll}
\boldsymbol{a}_{i} & =\text { Langrange Multiplier } \\
b & =\text { bias }
\end{array}
$$

Jika kelas tidak terpisah secara linear maka fungsi untuk permukaan ditentukan oleh persamaan 5 .

$$
f(x)-\operatorname{sign}\left(\sum=1 a_{i} y k(x, y)+b\right)
$$

Dimana:

$$
\begin{array}{ll}
a_{i} & =\text { Langrange Multiplier } \\
b & =\text { bias } \\
k(x, y) & =\text { Fungsi Kernel }
\end{array}
$$

Terdapat beberapa fungsi kernel yang digunakan untuk menyelesaikan masalah pada SVM nonlinear dapat dilihat pada persamaan 6 hingga 8 .

Fungsi Kernel Linear:

$$
k(x, y)=x, y
$$

Fungsi Kernel Polynomial:

$$
k(x, y)=(1+x, y)^{q}, q=1,2, \ldots, N
$$

Fungsi Kernel Radian Basis

$$
k(x, y)=\exp \frac{\left(-\|x-y\|^{2}\right)}{2 \sigma^{2}}
$$

\subsection{Multiclass SVM}

Metode yang umum digunakan untuk mengimplementasikan multi class SVM dengan pendekatan yang pertama adalah Metode OneAgainst-All dan Metode One-Against-One. Menggunakan Metode One-Against-One, mengharuskan setiap model klasifikasi dilatih pada data dari dua kelas. Terdapat beberapa metode untuk melakukan pengujian setelah keseluruhan model klasifikasi selesai dibangun. Salah satunya adalah metode voting Sembiring (2017).

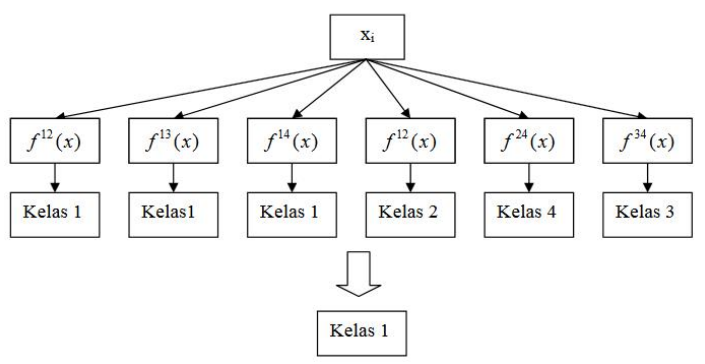

Gambar 2. Klasifikasi dengan One-Against-One

Kelas dari data $\mathrm{x}$ akan ditentukan dari jumlah suara terbanyak. Jika terdapat dua buah kelas yang jumlah suaranya sama, maka kelas yang indeksnya lebih kecil dinyatakan sebagai kelas dari data. Jadi pada pendekatan ini terdapat $k(k-1) / 2$ buah permasalahan quadratic programming yang masing - masing memiliki $2 n / k$ variabel (n adalah jumlah data pelatihan).

\subsection{Metode Sequential Training SVM}

Metode Sequential Training merupakan metode yang digunakan untuk training data agar menghasilkan hyperplane yang optimal Kusuma (2016).

1. Melakukan perhitungan kernel dan melakukan inisialisasi parameter - parameter SVM seperti contoh nilai $\alpha_{i}=0 ; \varepsilon=0,001$; $\gamma=0,01 ; \lambda=1 ; \quad \mathrm{C}=1$; dan nilai Iterasi maksimum $=3$.

2. Menghitung matriks Hessian

$$
D_{i}=y_{i} y_{i}\left(K\left(x_{i}, x_{i}\right)+\lambda^{2}\right)
$$

3. Melakukan iterasi untuk setiap iterasi $=1,2$, $3, \ldots, n$

Menghitung nilai Ei

$$
\mathrm{E}_{\mathrm{i}}=\sum_{j-2}^{n} \alpha_{i} D_{i j}
$$

Menghitung nilai $\gamma$ dan $\delta \alpha_{i}$

$$
\begin{aligned}
& \gamma=\frac{\text { Fonstanta }}{\max D_{i j}}=0,008 \\
& \delta \Omega_{i}=\min \left[\max \left[\gamma\left(1-E_{i}\right), \alpha_{i}\right], C-\alpha_{i}\right]
\end{aligned}
$$

Memperbarui nilai $\alpha_{\text {! }}$

$$
\alpha_{i}=\alpha_{i}+\delta \alpha
$$


4. Proses 1,2 , dan 3 diulangi hingga nilai $\delta \alpha$ mencapai konvergen $(|\delta \alpha|<\varepsilon)$ dan atau ketika nilai iterasi sudah mencapai nilai maksimum, maka iterasi dihentikan.

5. Menghitung nilai $\boldsymbol{w} \cdot \boldsymbol{x}^{+}$dan $\boldsymbol{w} \cdot \boldsymbol{x}^{-}$untuk mendapatkan nilai bias.

$$
\begin{gathered}
w \cdot x^{+}=\alpha_{i} \cdot y \cdot K\left(x, x^{-}\right) \\
w \cdot x^{-}=\alpha_{i} \cdot y \cdot K\left(x, x^{-}\right) \\
b--\frac{1}{2}\left(w \cdot x^{+}+w \cdot x^{-}\right)
\end{gathered}
$$

Keterangan:

$K\left(x, x^{+}\right)$: Nilai kernel data $\mathrm{x}$ dengan data $\mathrm{x}$ kelas positif yang memiliki nilai $\alpha$ tertinggi.

$K\left(x, x^{-}\right)$: Nilai kernel data $\mathrm{x}$ dengan data $\mathrm{x}$ kelas negatif yang memiliki nilai $\alpha$ tertinggi.

b : nilai bias

\subsection{Akurasi}

Akurasi merupakan nilai yang menunjukkan seberapa besar ketepatan yang didapatkan dari sebuah testing klasifikasi. Cara menghitung akurasi dapat menggunakan rumus:

Nilai akurasi $=\frac{z \text { hasil pradihsi henar }}{E \text { data uji hesqurwhan }} \times 100 \%$

\section{Metodologi}

\subsection{Desain Penelitian}

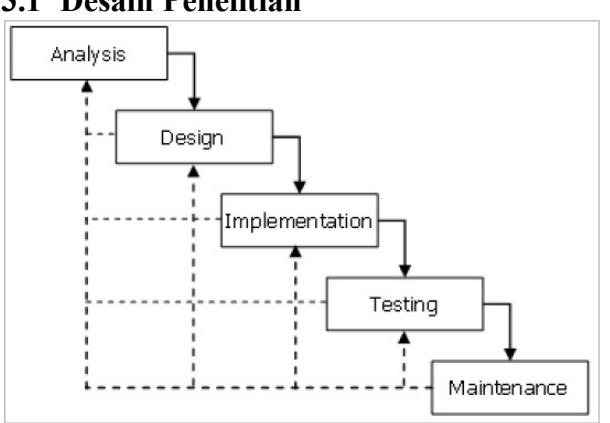

Gambar 3. Diagram Blok Penelitian

\section{Perancangan}

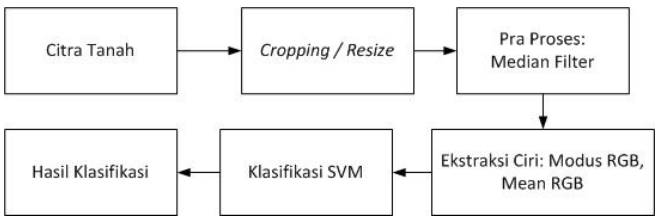

Gambar 4. Blok Diagram Alur Sistem

Data masukan untuk penelitian ini adalah citra digital dengan keluaran berupa hasil klasifikasi. Proses dimulai dengan melakukan cropping / resize pada citra tanah input menjadi 170x200, apabila citra tersebut belum berukuran 170x200. Namun karena penulis menggunakan data citra yang telah berukuran 170x200, maka proses cropping dan resize tidak perlu dilakukan. Kemudian melakukan proses pengurangan noise pada citra inputan menggunakan median filter. Setelah didapatkan citra tanpa noise, dilakukan proses perhitungan Modus dan Mean RGB untuk mendapatkan ciri dari warna. Kemudian melakukan proses perhitungan normalisasi data untuk mendapatkan data dalam range yang tidak terlalu besar. Proses berikutnya melakukan perhitungan klasifikasi menggunakan metode SVM untuk mendapatkan hasil klasifikasi.

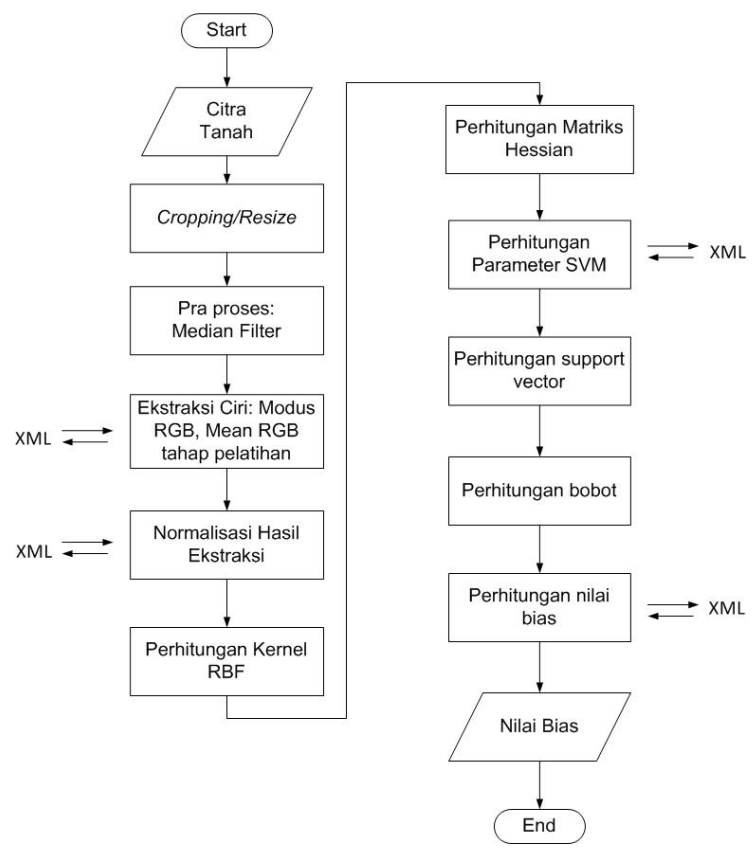

Gambar 5. Flowchart Training

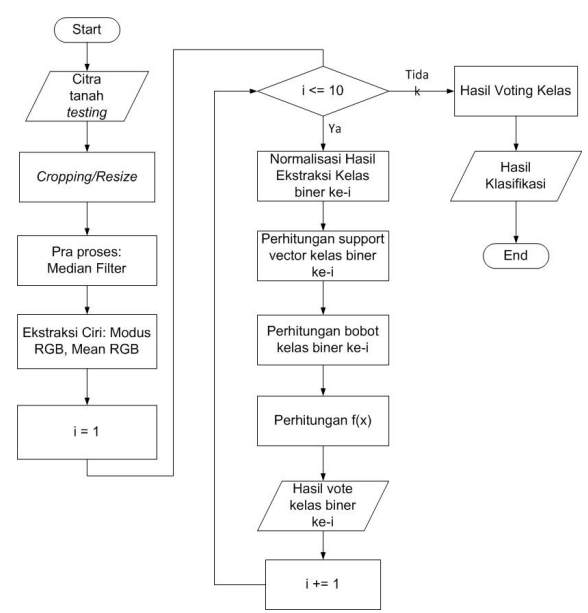

Gambar 6. Flowchart Testing 


\section{Uji coba dan Pembahasan}

\subsection{Pengujian Tingkat Akurasi}

Pengujian tingkat akurasi digunakan untuk menguji seberapa besar sistem deteksi warna tanah dengan menerapkan metode Support Vector Machine ini berhasil. Pada pengujian ini penulis menggunakan sistem offline (tidak realtime) dengan memanfaatkan citra tanah yang telah diperoleh oleh penulis sebelumnya.

Pada pengujian ini menggunakan sebanyak 15 sampel tanah yang terdiri dari index warna $5 \mathrm{Y}$ 3/1, 10 YR 3/2, 10 YR 5/4, 2.5 YR 4/2, dan 7.5 YR 5/6 yang diekstraksi menggunakan fitur modus dan mean. Berikut merupakan data sampel testing beserta hasil pengujian deteksi warna tanah dengan menerapkan metode Support Vector Machine.

Tabel. Data Sampel Testing

\begin{tabular}{|c|c|}
\hline Jumlah Data Tanah & Index Warna \\
\hline 3 buah & 5 Y 3/1 \\
\hline 3 buah & 10 YR 3/2 \\
\hline 3 buah & 10 YR 5/4 \\
\hline 3 buah & 2.5 YR 4/2 \\
\hline 3 buah & 7.5 YR 5/6 \\
\hline
\end{tabular}

Pengujian dilakukan menggunakan parameter lamda $=0,5$, gamma $=0,01$, complexity $=1$, epsilon $=0,001$, dan iterasi maksimum $=3$.

Tabel 2. Hasil Tingkat Akurasi Fitur Modus

\begin{tabular}{|c|c|c|c|c|}
\hline $\begin{array}{c}\text { Index } \\
\text { Warna }\end{array}$ & $\begin{array}{c}\text { Jumlah } \\
\text { Sampel }\end{array}$ & Sesuai & $\begin{array}{c}\text { Tidak } \\
\text { Sesuai }\end{array}$ & $\begin{array}{c}\text { Tingkat } \\
\text { Akurasi }\end{array}$ \\
\hline 5 Y 3/1 & 3 & 3 & 0 & $100 \%$ \\
\hline 10 YR 3/2 & 3 & 3 & 0 & $100 \%$ \\
\hline 10 YR 5/4 & 3 & 3 & 0 & $100 \%$ \\
\hline 2.5 YR 4/2 & 3 & 2 & 1 & $\begin{array}{c}66,67 \\
\%\end{array}$ \\
\hline 7.5 YR 5/6 & 3 & 3 & 0 & $100 \%$ \\
\hline \multicolumn{6}{|c|}{ Rata - rata akurasi } & $\begin{array}{c}93,33 \\
\%\end{array}$ \\
\hline
\end{tabular}

Tabel 3. Hasil Tingkat Akurasi Fitur Mean

\begin{tabular}{|c|c|c|c|c|}
\hline $\begin{array}{c}\text { Index } \\
\text { Warna }\end{array}$ & $\begin{array}{c}\text { Jumlah } \\
\text { Sampel }\end{array}$ & Sesuai & $\begin{array}{c}\text { Tidak } \\
\text { Sesuai }\end{array}$ & $\begin{array}{c}\text { Tingkat } \\
\text { Akurasi }\end{array}$ \\
\hline 5 Y 3/1 & 3 & 3 & 0 & $100 \%$ \\
\hline 10 YR 3/2 & 3 & 3 & 0 & $100 \%$ \\
\hline 10 YR 5/4 & 3 & 3 & 0 & $100 \%$ \\
\hline 2.5 YR 4/2 & 3 & 2 & 1 & $\begin{array}{c}66,67 \\
\%\end{array}$ \\
\hline 7.5 YR 5/6 & 3 & 3 & 0 & $100 \%$ \\
\hline \multicolumn{6}{|c|}{ Rata - rata akurasi } & $\begin{array}{c}93,33 \\
\%\end{array}$ \\
\hline
\end{tabular}

\subsection{Pengujian dan Analisis Parameter Lamda}

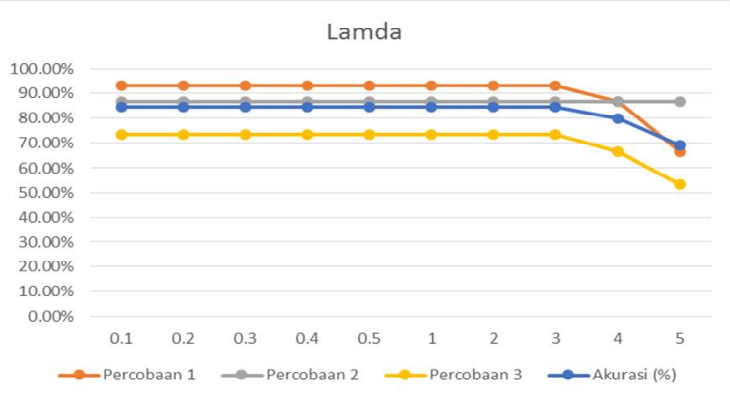

Gambar 7. Grafik Hasil Uji Parameter Lamda

Pada grafik pengujian dapat dilihat bahwa semakin besar lamda maka akurasi yang diperoleh akan semakin menurun. Hal ini karena semakin besar lamda, maka semakin besar pula kemungkinan terjadinya overfitting (atau disebut juga high variance) yang disebabkan oleh fungsi hipotesis yang sesuai (fit) pada hampir semua data dari training set tetapi tidak sesuai untuk data secara umum pada proses prediksi data baru selanjutnya.

\subsection{Pengujian dan Analisis Parameter C}

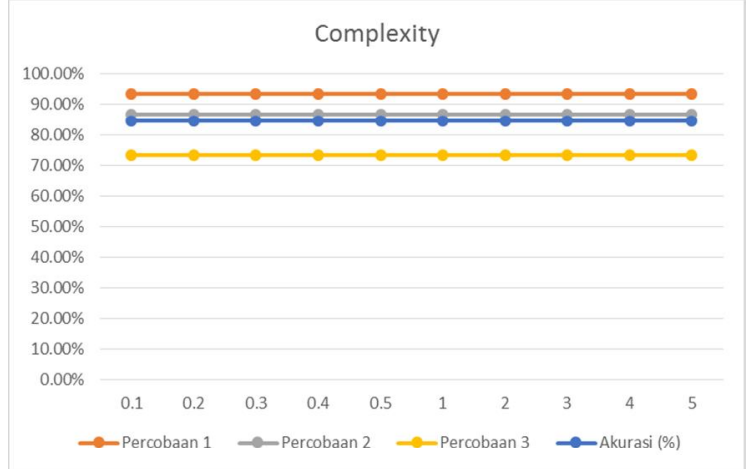

Gambar 8. Grafik Hasil Uji Parameter C

Dari Gambar 8 diperoleh hasil nilai $\mathrm{C}$ yang stabil dan tidak terjadi perubahan. Dari hal ini dapat diketahui bahwa mengubah nilai $\mathrm{C}$ dapat menghasilkan hyperplane yang berbeda maupun tidak tergantung dari data set yang dimiliki. Hal ini juga bisa dikarenakan SVM telah mengklasifikasi-kan data training secara tepat sehingga memperbesar maupun memperkecil nilai $\mathrm{C}$ tidak akan berpengaruh terhadap akurasi. 


\subsection{Pengujian dan Analisis Parameter Gamma}

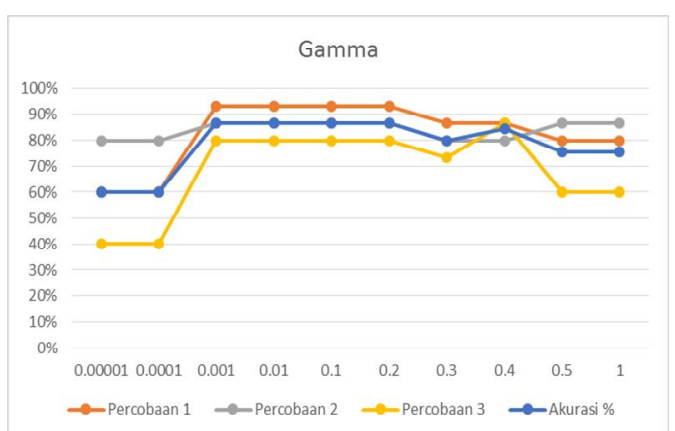

Gambar 9. Grafik Hasil Uji Parameter Gamma

Grafik menunjukkan bahwa pengujian terhadap nilai konstanta gamma memperoleh hasil akurasi rata - rata tertinggi pada nilai 0,$001 ; 0,01$; 0,1 ; dan 0,2 mencapai $86,67 \%$. Dari grafik tersebut dapat dijelaskan bahwa konstanta gamma memiliki pengaruh terhadap tingkat akurasi. Semakin besar nilai gamma, maka akurasi akan semakin menurun karena nilai gamma yang tinggi menyebabkan hyperplane hanya memperhatikan data terdekat saja sedangkan data yang jauh akan diabaikan sehingga data training tidak terpetakan dengan baik (underfitting). Sedangkan semakin kecil nilai gamma, titik terjauh akan semakin diperhatikan sehingga mampu menyebabkan overfitting.

\subsection{Pengujian dan Analisis Iterasi Maksimum}

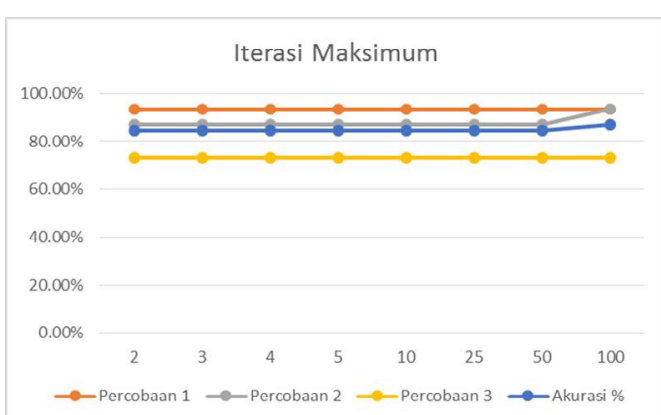

Gambar 10. Grafik Hasil Uji Iterasi Maksimum

Grafik menunjukkan bahwa akurasi terbaik terletak pada iterasi ke 100 . Rata - rata akurasi yang diperoleh pada iterasi ke 100 mencapai $86,66 \%$. Dari grafik tersebut dijelaskan bahwa iterasi maksimum cenderung stabil dan semakin besar jumlah iterasi maka semakin besar kemungkinan untuk memperoleh nilai $a_{i}$ yang konvergen akan semakin besar. Namun, iterasi maksimum tidak hanya dipengaruhi oleh jumlah maksimum iterasi melainkan juga jumlah $\varepsilon$ (epsilon) di mana iterasi akan berhenti jika nilai $(|\delta \alpha|<\varepsilon)$.

\section{Kesimpulan dan Saran \\ 6.1 Kesimpulan}

Penggunaan metode ekstraksi fitur warna modus dan mean untuk klasifikasi dengan metode Support Vector Machine berhasil melakukan klasifikasi pada citra tanah ke dalam lima kelas yang telah ditentukan sebelumnya yaitu $5 \mathrm{Y} \mathrm{3/1,}$ 10 YR 3/2, 10 YR 5/4, 2.5 YR 4/2, dan 7.5 YR $5 / 6$. Tingkat keberhasilan deteksi warna tanah menggunakan metode Support Vector Machine ini berhasil memperoleh nilai 93,33\% menggunakan fitur modus dan 93,33\% menggunakan fitur mean . Parameter - parameter yang digunakan antara lain lamda $=0,5$, gamma $=0,01$, complexity $=1$, epsilon $=0,001$, dan iterasi maksimum $=3$. Nilai parameter - parameter pada metode klasifikasi SVM yang diubah - ubah ternyata memberikan dampak terhadap perubahan nilai akurasinya. Dari pengujian pada parameter - parameter SVM yang telah dilakukan didapatkan nilai terbaik untuk parameter lamda adalah $0,1-0,5$ dan $1-3$, untuk parameter $\mathrm{C}$ tidak terdapat perubahan dengan rata - rata akurasi adalah $84,44 \%$, nilai terbaik untuk parameter konstanta gamma adalah 0,001, 0,01, 0,1 , dan 0,2 , sedangkan nilai terbaik untuk jumlah iterasi adalah 100 .

\subsection{Saran}

1. Diharapkan pada penelitian selanjutnya dapat mengklasifikasikan warna tanah ke dalam index warna kelas yang lebih bervariasi.

2. Diharapkan pada penelitian yang selanjutnya dilakukan penambahan terhadap variasi ekstraksi fitur untuk pendeteksian warna tanah tidak hanya modus dan mean RGB dari citra.

3. Diharapkan untuk penelitian selanjutnya dapat menggunakan kernel yang berbeda karena kernel yang lain memiliki karakter data yang berbeda.

\section{Daftar Pustaka:}

Sutanto,Rachman, (2005), "Dasar - Dasar Ilmu Tanah", Yogyakarta: Kanisius.

Jordan, Antonio, (2014), Soil Color Never Lies [online]. Available: http://blogs.egu.eu/divisions/sss/2014/ 03/30/soil-color-never-lies/.

Hardjowigeno, S, (1992), "Ilmu Tanah", Edisi Ketiga, Jakarta: PT. Mediyatama Sarana Perkasa.

Hardjowigeno, S, (1987), "Ilmu Tanah", Edisi Pertama, Jakarta: PT. Mediyatama Sarana Perkasa.

Madjid, A., (2007), “Dasar-Dasar Ilmu Tanah", Bahan Ajar Online Fakultas Pertanian Unsri.

Hermawati, Fajar Astuti, (2013), "Pengolahan Citra Digital", Yogyakarta: Penerbit ANDI. 
Rizal, Achmad, (2014), Pengolahan Citra [online], Available: http://achmadrizal.staff.telkomuniversity.ac.id/ pengolahan-citra/.

Robbani, Ihwanudien Hasan, et al., (2016), "Aplikasi Mobile Scotect : Aplikasi Deteksi Warna Tanah dengan Teknologi Citra Digital pada Android", JTIIK, vol. 3, No.1, pp.19-26, April 2016.

Woods, Richard E., Gonzales, Rafael E., (2008), "Digital Image Processing", Third Edition, New Jersey: Pearson Education.

Kusuma, Yoke, (2016), Implementasi Metode Support Vector Machine (SVM) Untuk Identifikasi Penyakit Daun Tanaman Kacang Tanah Menggunakan Gray-Level Coocurance Matrix (GLCM). Disertasi Sarjana Komputer pada FTIIK Universitas Brawijaya : tidak diterbitkan.

Sembiring, Krisantus, (2007), Penerapan Teknik Support Vector Machine untuk Pendeteksian Intrusi pada Jaringan [online]. Available : http://sutikno.blog.undip.ac.id/ files /2011/11/ tutorial - svm - bahasa - indonesia - oleh krisantus.pdf. 
Volume 4, Edisi 2, Februari 2018

H a 1 a $m$ a n | 138 